\title{
Effects of Abomasal Vegetable Oil Infusion on Splanchnic Nutrient Metabolism in Lactating Dairy Cows
}

\author{
J. A. Benson, ${ }^{1}$ C. K. Reynolds, ${ }^{2}$ P. C. Aikman, B. Lupoli, \\ and D. E. Beever \\ Centre for Dairy Research, Department of Agriculture, \\ The University of Reading, Earley Gate, RG6 6AT England
}

\begin{abstract}
Changes in the metabolism of nutrients by the portaldrained viscera (PDV) and liver may contribute to the reduction in dry matter intake (DMI) and other production responses generally observed in lactating dairy cows fed supplemental long-chain fatty acids (LCFA). In the present study, effects of a 7-d abomasal infusion of vegetable oil on arterial concentration and splanchnic (PDV and liver) metabolism of nutrients were measured in six cows at 55 (early lactation [ELAC]) and 111 (midlactation [MLAC]) d postpartum. Cows were fed for ad libitum DMI at 8-h intervals, and blood samples for measurement of splanchnic metabolism were obtained over $8 \mathrm{~h}$ beginning $2 \mathrm{~h}$ before feeding at $0830 \mathrm{~h}$. Blood flow for the PDV and liver was increased by oil infusion and was greater in ELAC, despite similar-feed DMI during blood sampling. Increased blood flow in ELAC was associated with greater liver oxygen removal and glucose release that accompanied greater milk yield. In contrast, oil infusion had no effect on splanchnic oxygen use. Greater blood flow during oil infusion may have been due to specific effects of intestinal LCFA supply on PDV blood flow. Net PDV release and liver removal of branchedchain volatile fatty acids (VFA) and ammonia were increased by oil infusion. Net PDV release of longer-chain (4 and 5 C) VFA and NEFA was greater in ELAC, but net PDV flux of other nutrients was not affected by lactation stage, possibly due to the similarity of feed DMI. Oil infusion increased arterial concentration and net PDV release and liver removal of NEFA, and it decreased net liver release and arterial concentration of glucose. Effects of oil infusion on liver glucose release were associated with decreased daily DMI. In ELAC, arterial concentration and net liver removal of NEFA were also increased,
\end{abstract}

\footnotetext{
Received August 17, 2001.

Accepted January 11, 2002

Corresponding author: C. K. Reynolds; e-mail: Reynolds.345@ osu.edu.

${ }^{1}$ Current address: Department of Animal Sciences, The University of Kentucky, Lexington, 40546.

${ }^{2}$ Current address: Department of Animal Sciences, The Ohio State University, OARDC, 1680 Madison Ave., Wooster 44691-4096.
}

but liver release of glucose was greater than in MLAC. Oil infusion and ELAC both increased net liver removal of L-lactate. The resulting decrease in net total splanchnic release of L-lactate in ELAC reflects decreased tissue energy balance of the cows. Generally, stage of lactation and relative milk yield had greater effects on metabolism of the liver than the PDV, in which metabolism was largely dictated by DMI. In the present study, there was little evidence to suggest an effect of stage of lactation on the metabolic response of the PDV and liver to postruminal LCFA supply.

(Key words: long-chain fatty acids, portal-drained viscera, liver, metabolism)

Abbreviation key: ELAC = early lactation, LCFA = long-chain fatty acids, $\mathbf{M E}=$ metabolizable energy, MLAC = midlactation, $\mathbf{P C V}=$ packed-cell volume, $\mathbf{P D V}$ = portal-drained viscera, $\mathbf{R Q}=$ respiratory quotient, $\mathbf{T S P}$ $=$ total splanchnic.

\section{INTRODUCTION}

The diet of lactating dairy cows is often supplemented with rumen-inert fat in an attempt to increase energy intake and milk production, while minimizing inhibitory effects of fatty acids on ruminal microbes (Palmquist, 1994). However, depression in DMI and effects on blood concentrations of VFA, glucose and other products of digestion have been observed, even when long-chain fatty acids (LCFA) are infused postruminally to preclude direct rumen effects (Grummer and Carroll, 1991). Although effects of dietary fat on in vivo liver lipid metabolism in preruminant calves are reported (Leplaix-Charlat et al., 1996), we are currently aware of no other published studies in ruminants that have examined the effects of postruminal LCFA supply on portal-drained viscera (PDV) and liver (total splanchnic [TSP]) tissue metabolism. Splanchnic metabolism is important in determining the availability of precursors for milk and body tissue synthesis, and thus production responses to supplemental fat. In addition, the liver is considered an important source of signals that may have a role controlling intake (Friedman, 1998). Increased liver oxidation 
of long-chain fatty acids reduces intake in rats (Scharrer and Langhans, 1986) and may be responsible for decreased DMI in lactating cows fed fat. Therefore, changes in splanchnic nutrient metabolism may be indicative of the metabolic responses and mechanisms underlying intake and production responses to dietary fat supplementation. The objective of the present experiment was to measure the effects of postruminal infusion of vegetable oil and stage of lactation on net flux of nutrients across the PDV and liver of dairy cows.

\section{MATERIALS AND METHODS}

\section{Cows, Diet, and Treatments}

Details of cows, their diet, treatments, and lactation performance were described by Benson et al. (2001). Briefly, six rumen-fistulated, multicatheterized Holstein $\times$ British Friesian cows were fed a TMR $(20 \%$ grass silage, $30 \%$ dehydrated alfalfa, and $50 \%$ concentrates on a DM basis) for ad libitum intake. Daily rations were offered in equal meals provided at 0830,1630 , and 2230 h. Treatments consisted of 7-d abomasal infusions of 400 $\mathrm{g} / \mathrm{d}$ water or a 50:50 mixture (by weight) of sunflower and rapeseed oils (oil) providing mostly (91\%) unsaturated LCFA as triglycerides, which immediately followed water infusions. Abomasal infusion lines were established via a rumen fistula and the reticulo-omasal orifice. Infusions began at an average of $55 \mathrm{~d}$ (early lactation [ELAC]) and $111 \mathrm{~d}$ postpartum (mid lactation [MLAC]).

\section{Blood Sampling Protocol}

Benson and Reynolds (2001) described details of the blood sampling protocol and measurement of blood flow. Briefly, 25 sets of blood samples were obtained simultaneously from the mesenteric artery, hepatic portal vein, and hepatic vein on $\mathrm{d} 7$ of water and subsequent oil infusions during an 8 -h period (0630 to $1430 \mathrm{~h}$ ) that included feeding at $0830 \mathrm{~h}$. Continuous mesenteric vein infusion of $\rho$-aminohippurate for measurement of blood flow began $1 \mathrm{~h}$ before blood sampling. Blood for nutrient analysis was collected in syringes treated with potassium EDTA $(1.6 \mathrm{mg} / \mathrm{ml}$ blood), whereas blood for gas analysis was collected in syringes treated with heparin (125 U/ $\mathrm{ml}$ of blood). Aliquots of blood were immediately frozen in liquid nitrogen for later analysis of ammonia, urea, and individual VFA concentration. Remaining blood was centrifuged at $3000 \mathrm{rpm}$ and $4^{\circ} \mathrm{C}$ for $20 \mathrm{~min}$ and aliquots of plasma immediately frozen in liquid nitrogen for later analysis of L-lactate, BHBA, and NEFA concentration. Tubes containing blood and plasma were immersed in ice until analyzed or frozen as soon as possible. While 25 sample sets were obtained, for analyses other than $\rho$ aminohippurate and glucose samples were pooled across contiguous sampling times to reduce analytical requirements. This pooling reduced the total number of samples analyzed for each sampling site within a cow-sampling period to 17 for ammonia, urea, BHBA, NEFA, and Llactate; 11 for blood gases; and 8 for VFA.

\section{Sample Analysis}

Measurements of blood packed-cell volume (PCV), hemoglobin, partial pressure of oxygen $\left(\mathrm{O}_{2}\right)$ and carbon dioxide $\left(\mathrm{CO}_{2}\right)$, and $\mathrm{pH}$ were obtained as soon as possible after the samples were collected using a blood gas analyzer (Instrumentation Laboratories 1302, Warrington, Cheshire, UK). Hemoglobin concentration of blood samples was measured using a commercial kit (Boehringer Mannheim, Lewes, UK), and blood PCV was determined by microcentrifugation. Plasma glucose and $\rho$-aminohippurate concentrations were measured as soon as possible on a Cobas Mira analyzer (Roche Diagnostic Products, Welwyn Garden City, UK) using enzymatic (Glucose Trinder Assay; Sigma-Aldrich Ltd., Poole, UK) and colorimetric assays (Benson and Reynolds, 2001), respectively. Blood samples for analysis of ammonia and urea content were thawed and diluted with $0.9 \mathrm{part}(\mathrm{vol} / \mathrm{vol})$ ice-cold water and $0.1 \mathrm{part}$ (vol/vol) ice-cold $6 \mathrm{M}$ perchloric acid. Supernatants obtained following centrifugation at $10,000 \times g$ for $40 \mathrm{~min}$ at $4^{\circ} \mathrm{C}$ were neutralized with 2 $M$ potassium bicarbonate and centrifuged for $20 \mathrm{~min}$ at $1,800 \times g$ and $4^{\circ} \mathrm{C}$. The resulting supernatants were analyzed for ammonia concentration using an enzymatic assay (Kun and Kearney, 1974) or frozen $\left(-20^{\circ} \mathrm{C}\right)$ for later analysis of urea concentration using a manual version of an automated colorimetric assay described by Reynolds et al. (1988b).

Concentrations of VFA were measured by capillary GLC using a $30-\mathrm{m} \times 0.25-\mathrm{mm}$ Stabilwax-DA column (Thames Restek, Slough, UK). Blood samples for VFA analysis were prepared as described (Reynolds et al., 1986), except that the anion exchange resin was changed from the BioRex 5 resin (BioRad, Hemel Hempstead, UK) used in the original procedure to AG4X4. The manufacturer changed the BioRex 5 resin after the original procedure for sample cleanup was validated (Reynolds et al., 1986). Using the AG4X4 resin, the recoveries of VFA added to blood during deproteinization, and adjusted for recovery of added internal standard, averaged $99,99,99,98,100$, and $96 \%$ for acetate, propionate, $n-$ butyrate, i-butyrate, n-valerate, and i-valerate, respectively. L-Lactate (Gutman and Wahlfeld, 1974), BHBA (Reynolds et al., 1988a), and NEFA (Reynolds et al., 1988a) concentrations of thawed plasma samples were measured using enzymatic methods adapted for use on the Cobas Mira. 
Table 1. Splanchnic plasma and blood flow and packed-cell volume (PCV) in response to abomasal infusion of water or oil at an average of 55 (early lactation [ELAC]) and 111 (midlactation [MLAC]) d postpartum.

\begin{tabular}{|c|c|c|c|c|c|c|c|c|}
\hline & \multicolumn{4}{|c|}{ Lactation stage } & \multirow[b]{3}{*}{ SEM } & \multicolumn{3}{|c|}{ Significance, $P<$} \\
\hline & \multicolumn{2}{|c|}{ ELAC } & \multicolumn{2}{|c|}{ MLAC } & & \multirow{2}{*}{$\begin{array}{l}\text { Lactation } \\
\text { stage }\end{array}$} & \multirow[b]{2}{*}{ Infusion } & \multirow{2}{*}{$\begin{array}{l}\text { Stage } \times \\
\text { infusion }\end{array}$} \\
\hline & Water & Oil & Water & Oil & & & & \\
\hline \multicolumn{9}{|c|}{ Plasma flow, L/h } \\
\hline Arterial & 463 & 468 & 422 & 380 & 44 & 0.18 & 0.70 & 0.61 \\
\hline Hepatic & 2117 & 2272 & 1929 & 2080 & 48 & 0.01 & 0.01 & 0.97 \\
\hline Portal & 1655 & 1807 & 1511 & 1702 & 41 & 0.02 & 0.01 & 0.65 \\
\hline \multicolumn{9}{|c|}{ Blood flow, L/h } \\
\hline Arterial & 640 & 629 & 534 & 526 & 77 & 0.21 & 0.91 & 0.99 \\
\hline Hepatic & 2932 & 3118 & 2591 & 2887 & 85 & 0.01 & 0.02 & 0.55 \\
\hline Portal & 2296 & 2492 & 2060 & 2389 & 67 & 0.03 & 0.01 & 0.35 \\
\hline $\mathrm{PCV}, \%^{1}$ & 28 & 27 & 29 & 28 & 0.3 & 0.01 & 0.03 & 0.95 \\
\hline \multicolumn{9}{|c|}{ Hemoglobin, g/L } \\
\hline Arterial & 95.4 & 92.6 & 95.4 & 91.4 & 1.3 & 0.68 & 0.02 & 0.65 \\
\hline Mean $^{1}$ & 94.6 & 92.1 & 94.2 & 90.7 & 1.4 & 0.54 & 0.05 & 0.75 \\
\hline
\end{tabular}

${ }^{1}$ Average for arterial, portal vein, and hepatic vein samples.

\section{Calculations and Statistical Analysis}

Plasma flow for the PDV and liver was calculated from $\rho$-aminohippurate dilution as described previously (Reynolds et al., 1988b), and blood flow was calculated from plasma flow and PCV. Concentrations of $\mathrm{O}_{2}$ and $\mathrm{CO}_{2}$ in blood were calculated using measured partial pressures of $\mathrm{O}_{2}$ and hemoglobin concentrations or partial pressure of $\mathrm{CO}_{2}$ and $\mathrm{pH}$, respectively (Oddy et al., 1984). Net flux of nutrients and gases across the PDV, liver, and TSP tissues was calculated as the product of venousarterial concentration difference multiplied by plasma flow (Reynolds et al., 1988b). The fluxes calculated are net values, often the result of both metabolite release into and uptake from blood. Using venous-arterial differences, a negative flux represents a net removal from blood and a positive flux represents a net production or release.

The effects of cow, abomasal infusion (water or oil), stage of lactation (ELAC or MLAC), and the interaction between infusion and stage were tested using residual variance with the GLM procedure of SAS (1999). Only 23 of 24 sets of blood samples were obtained due to the loss of one cow's carotid artery catheter immediately before blood sampling for oil infusion in ELAC. Least squares means reported were all obtained using the full statistical model for ANOVA, and any standard error of the means presented is for $n=6$. Due to the small number of cows used $(\mathrm{n}=6)$, differences were considered significant at $P<0.10$.

\section{RESULTS}

\section{Blood Flow and Packed-cell Volume}

Portal vein and liver plasma and total blood flow (Table $1)$ were significantly increased by oil infusion $(P<0.02)$ and were greater in ELAC than MLAC $(P<0.03)$. There was no effect of oil infusion or stage of lactation on hepatic artery blood flow. Mean PCV for the three blood vessels sampled (Table 1) was decreased in response to oil infusion $(P<0.03)$ and was greater in MLAC than ELAC $(P$ $<0.01)$. Both arterial $(P<0.02)$ and mean $(P<0.05)$ hemoglobin concentration (Table 1 ) were decreased by oil infusion.

\section{Volatile Fatty Acids}

In ELAC, arterial concentration of total VFA (Table 2) was decreased by oil infusion, whereas in MLAC oil infusion increased arterial concentration of total VFA (lactation stage by infusion interaction $[P<0.09]$ ). This response was largely due to changes in arterial acetate concentration (Table 2), which accounted for $95 \%$ of total VFA concentration in arterial blood and had a similar lactation stage by infusion interaction $(P<0.04)$. Arterial propionate concentration was greater in MLAC than in ELAC $(P<0.01)$ and was decreased by oil infusion $(P<$ $0.01)$. Arterial n-butyrate concentration also showed a stage of lactation $\times$ infusion interaction $(P<0.03)$, but the response was inverse to that of acetate; it was increased by oil infusion in ELAC but decreased by oil infusion in MLAC (Table 2). Arterial concentration of ibutyrate, i-valerate, and n-valerate were much lower than the three major VFA, but arterial concentration of i-butyrate $(P<0.07)$ and i-valerate $(P<0.01)$ were greater in ELAC than in MLAC and were not affected by oil infusion $(P>0.25)$. In contrast, arterial n-valerate concentration was greater in MLAC than ELAC $(P<0.02)$ and increased by oil infusion $(P<0.01$ [Table 2]).

Overall, there were no significant effects $(P>0.16)$ of either stage of lactation or oil infusion on net PDV, liver, or TSP fluxes of total VFA (Table 2), but in ELAC, net 
Table 2. Arterial concentrations and net flux of VFA across portal-drained viscera (PDV), liver, and total splanchnic (TSP) tissues during abomasal infusion of water or oil at an average of 55 (early lactation [ELAC]) and 111 (midlactation [MLAC]) d postpartum.

\begin{tabular}{|c|c|c|c|c|c|c|c|c|}
\hline & \multicolumn{4}{|c|}{ Lactation stage } & \multirow[b]{3}{*}{ SEM } & \multicolumn{3}{|c|}{ Significance, $P<$} \\
\hline & \multicolumn{2}{|c|}{ ELAC } & \multicolumn{2}{|c|}{ MLAC } & & \multirow{2}{*}{$\begin{array}{l}\text { Lactation } \\
\text { stage }\end{array}$} & \multirow[b]{2}{*}{ Infusion } & \multirow{2}{*}{$\begin{array}{l}\text { Stage } \times \\
\text { infusion }\end{array}$} \\
\hline & Water & Oil & Water & Oil & & & & \\
\hline \multicolumn{9}{|c|}{ Arterial concentration, $\mu \mathrm{M}$} \\
\hline Acetate & 2225 & 2116 & 2164 & 2259 & 47 & 0.39 & 0.89 & 0.04 \\
\hline Propionate & 67.6 & 58.5 & 71.9 & 68.1 & 2.10 & 0.01 & 0.01 & 0.24 \\
\hline n-Butyrate & 28.4 & 32.9 & 26.7 & 25.0 & 1.30 & 0.01 & 0.33 & 0.03 \\
\hline n-Valerate & 6.3 & 7.5 & 6.5 & 8.1 & 0.20 & 0.02 & 0.01 & 0.35 \\
\hline i-Butyrate & 5.4 & 5.7 & 5.0 & 5.1 & 0.30 & 0.07 & 0.46 & 0.85 \\
\hline i-Valerate & 8.7 & 9.4 & 7.2 & 7.6 & 0.50 & 0.01 & 0.25 & 0.82 \\
\hline Total $^{1}$ & 2331 & 2237 & 2287 & 2373 & 4.90 & 0.37 & 0.94 & 0.09 \\
\hline \multicolumn{9}{|c|}{ Net PDV flux, mmol/h } \\
\hline Acetate & 3331 & 3142 & 3185 & 3449 & 96.0 & 0.42 & 0.71 & 0.03 \\
\hline Propionate & 1162 & 1196 & 1177 & 1174 & 35.0 & 0.92 & 0.67 & 0.61 \\
\hline n-Butyrate & 235 & 240 & 209 & 213 & 9.0 & 0.01 & 0.66 & 0.95 \\
\hline n-Valerate & 52.9 & 51.4 & 46.1 & 47.7 & 2.70 & 0.07 & 0.95 & 0.62 \\
\hline i-Butyrate & 33.6 & 39.4 & 31.3 & 34.3 & 1.00 & 0.01 & 0.01 & 0.17 \\
\hline i-Valerate & 56.2 & 64.0 & 52.9 & 57.6 & 2.00 & 0.02 & 0.01 & 0.46 \\
\hline Total $^{1}$ & 4871 & 4740 & 4703 & 4975 & 135.0 & 0.82 & 0.62 & 0.16 \\
\hline \multicolumn{9}{|c|}{ Net liver flux, $\mathrm{mmol} / \mathrm{h}$} \\
\hline Acetate & 1074 & 988 & 911 & 751 & 101.0 & 0.06 & 0.25 & 0.73 \\
\hline Propionate & -1089 & -1110 & -1093 & -1100 & 33.0 & 0.93 & 0.70 & 0.85 \\
\hline n-Butyrate & -189 & -192 & -168 & -179 & 8.0 & 0.03 & 0.38 & 0.62 \\
\hline n-Valerate & -57.1 & -56.2 & -50.9 & -52.7 & 2.70 & 0.10 & 0.88 & 0.64 \\
\hline i-Butyrate & -31.4 & -36.4 & -28.8 & -32.3 & 0.90 & 0.01 & 0.01 & 0.47 \\
\hline i-Valerate & -52.0 & -56.7 & -48.3 & -53.5 & 1.80 & 0.07 & 0.01 & 0.90 \\
\hline Total & -345 & -519 & -464 & -658 & 112.0 & 0.29 & 0.13 & 0.94 \\
\hline \multicolumn{9}{|c|}{ Net total splanchnic flux, $\mathrm{mmol} / \mathrm{h}$} \\
\hline Acetate & 4404 & 4037 & 4079 & 4144 & 124 & 0.41 & 0.25 & 0.10 \\
\hline Propionate & 80 & 76 & 84 & 74 & 4.4 & 0.90 & 0.16 & 0.47 \\
\hline n-Butyrate & 47 & 51 & 42 & 36 & 3.5 & 0.01 & 0.74 & 0.20 \\
\hline n-Valerate & -4.2 & -5.2 & -4.8 & -5.1 & 2.70 & 0.10 & 0.88 & 0.64 \\
\hline i-Butyrate & 2.2 & 3.6 & 2.5 & 1.9 & 0.54 & 0.23 & 0.47 & 0.08 \\
\hline i-Valerate & 4.3 & 7.0 & 4.6 & 4.1 & 0.82 & 0.13 & 0.19 & 0.06 \\
\hline Total & 4531 & 4156 & 4207 & 4281 & 150.0 & 0.47 & 0.29 & 0.11 \\
\hline
\end{tabular}

${ }^{1}$ Total is the sum of acetate, propionate, n-butyrate, n-valerate, i-butyrate, and i-valerate.

PDV release of n-butyrate $(P<0.01)$, i-butyrate $(P<$ $0.01)$, i-valerate $(P<0.02)$, and n-valerate $(P<0.07)$ were all greater than in MLAC. Net release of acetate and net removal of n-butyrate, i-butyrate, i-valerate, and nvalerate by the liver were also greater in ELAC than in MLAC $(P<0.10$ [Table 2]). There was a net TSP release for all VFA except n-valerate, for which there was a slight net uptake, but net release of acetate accounted for $97 \%$ of the net TSP release of total VFA. Net TSP removal of $n$-valerate was greater in MLAC than in ELAC $(P<0.10)$, whereas net TSP release of n-butyrate was greater in ELAC than MLAC $(P<0.01)$.

Net PDV release of i-butyrate and i-valerate and their net removal by the liver were increased in response to oil infusion $(P<0.01$ [Table 2]). There also were stage of lactation $\times$ infusion interactions for net acetate flux across both PDV and TSP tissues $(P<0.10)$. For both tissue beds, net acetate flux was decreased by oil infusion in ELAC and increased by oil infusion in MLAC (Table
3). In contrast, net TSP release of i-butyrate $(P<0.08)$ and i-valerate $(P<0.06)$ was increased by oil infusion in ELAC and decreased by oil infusion in MLAC.

\section{Ammonia and Urea}

There were no effects of infusion or stage of lactation on arterial concentration of ammonia or urea $(P>0.46$ [Table 3]). On a net basis, PDV urea removal averaged $33 \%$ of urea released by the liver, whereas ammonia $\mathrm{N}$ removal by the liver accounted for $70 \%$ of liver release of urea. There was no effect of stage of lactation on net PDV, liver, or TSP flux of ammonia or urea $(P>0.28$ [Table 3]). Infusion of oil increased net PDV release $(P$ $<0.01)$ and liver uptake $(P<0.02)$ of ammonia, while net TSP flux was unchanged $(P>0.92)$. Numerical increases in net liver release of urea (Table 3) accounted for $69 \%$ of the increase in ammonia nitrogen removal by the liver when oil was infused. 
Table 3. Arterial concentration and net flux of blood metabolites and gases across portal-drained viscera (PDV), liver and total splanchnic (TSP) tissues, and PDV and liver respiratory quotient (RQ) during abomasal infusion of water or oil at an average of 55 (early lactation [ELAC]) and 111 (midlactation [MLAC]) d postpartum.

\begin{tabular}{|c|c|c|c|c|c|c|c|c|}
\hline & \multicolumn{4}{|c|}{ Lactation stage } & \multirow[b]{3}{*}{ SEM } & \multicolumn{3}{|c|}{ Significance, $P<$} \\
\hline & \multicolumn{2}{|c|}{ ELAC } & \multicolumn{2}{|c|}{ MLAC } & & \multirow{2}{*}{$\begin{array}{l}\text { Lactation } \\
\text { stage }\end{array}$} & \multirow[b]{2}{*}{ Infusion } & \multirow{2}{*}{$\begin{array}{l}\text { Stage } \times \\
\text { infusion }\end{array}$} \\
\hline & Water & Oil & Water & Oil & & & & \\
\hline \multicolumn{9}{|c|}{ Arterial concentration, $\mathrm{m} M$} \\
\hline Ammonia & 0.346 & 0.328 & 0.315 & 0.334 & 0.015 & 0.46 & 0.99 & 0.27 \\
\hline Urea & 5.47 & 5.72 & 5.56 & 5.61 & 0.216 & 0.97 & 0.51 & 0.65 \\
\hline $\mathrm{O}_{2}$ & 5.41 & 5.24 & 5.38 & 5.16 & 0.078 & 0.53 & 0.03 & 0.75 \\
\hline $\mathrm{CO}_{2}$ & 27.65 & 27.48 & 27.71 & 27.68 & 0.377 & 0.75 & 0.81 & 0.85 \\
\hline \multicolumn{9}{|c|}{ Net PDV flux, mmol/h } \\
\hline Ammonia & 891 & 1029 & 878 & 986 & 38 & 0.50 & 0.01 & 0.71 \\
\hline Urea & -218 & -212 & -271 & -267 & 46 & 0.28 & 0.92 & 0.99 \\
\hline $\mathrm{O}_{2}$ & -4345 & -4316 & -4095 & -4220 & 182 & 0.38 & 0.81 & 0.69 \\
\hline $\mathrm{CO}_{2}$ & 1683 & 1436 & 1580 & 1012 & 283 & 0.38 & 0.19 & 0.60 \\
\hline PDV RQ & 0.42 & 0.40 & 0.45 & 0.28 & 0.085 & 0.60 & 0.31 & 0.44 \\
\hline \multicolumn{9}{|c|}{ Net liver flux, $\mathrm{mmol} / \mathrm{h}$} \\
\hline Ammonia & -937 & -1083 & -941 & -1029 & 43 & 0.58 & 0.02 & 0.53 \\
\hline Urea & 686 & 731 & 703 & 739 & 35 & 0.73 & 0.28 & 0.91 \\
\hline $\mathrm{O}_{2}$ & -4401 & -4398 & -3988 & -3770 & 229 & 0.05 & 0.65 & 0.66 \\
\hline $\mathrm{CO}_{2}$ & 2674 & 2641 & 2854 & 2560 & 336 & 0.89 & 0.65 & 0.72 \\
\hline Liver RQ & 0.59 & 0.63 & 0.69 & 0.67 & 91 & 0.45 & 0.86 & 0.76 \\
\hline \multicolumn{9}{|c|}{ Net TSP flux, $\mathrm{mmol} / \mathrm{h}$} \\
\hline Ammonia & -49 & -52 & -63 & -56 & 15 & 0.57 & 0.92 & 0.76 \\
\hline Urea & 473 & 526 & 419 & 479 & 50 & 0.35 & 0.31 & 0.95 \\
\hline $\mathrm{O}_{2}$ & -8646 & -8735 & -8073 & -7969 & 333 & 0.08 & 0.99 & 0.79 \\
\hline $\mathrm{CO}_{2}$ & 4338 & 4073 & 4338 & 3471 & 346 & 0.41 & 0.14 & 0.42 \\
\hline
\end{tabular}

\section{Blood Gases}

Arterial blood $\mathrm{O}_{2}$ concentration was decreased $(P<$ 0.03 ) by oil infusion but was unaffected by stage of lactation $(P>0.53$ [Table 3]). Infusion of oil had no effect on net PDV, liver, or TSP removal of $\mathrm{O}_{2}(P>0.65$ [Table $3]$ ). Oxygen removal by the TSP was greater in ELAC than MLAC $(P<0.08)$ due to an increase in liver removal $(P<0.05)$, as PDV uptake did not differ $(P>0.38)$. Arterial $\mathrm{CO}_{2}$ concentrations were unaffected by oil infusion $(P>0.81)$ and stage of lactation $(P>0.75$ [Table 3]). Similarly, net flux of $\mathrm{CO}_{2}$ across PDV, liver, and TSP tissues and respiratory quotient $\left(\mathbf{R Q}\right.$ [net $\mathrm{CO}_{2}$ release/ net $\mathrm{O}_{2}$ removal]) for the PDV and liver were not affected by stage of lactation or infusion $(P>0.14$ [Table 3] $)$.

\section{Plasma Metabolites}

Arterial glucose concentration $(P<0.01)$ and net liver and TSP glucose release were decreased by the oil infusion $(P<0.06$ [Table 4]). Arterial glucose concentration was greater in MLAC than ELAC $(P<0.01)$, but both liver and TSP glucose production were greater in ELAC $(P<0.01)$. The slight net removal of glucose by the PDV tissues was unaffected by oil infusion $(P>0.6)$ or stage of lactation $(P>0.2)$.

Net removal of L-lactate by liver was increased $(P<$ 0.05 ) by oil infusion and, as net PDV release was unaf- fected $(P>0.68)$, net TSP release of L-lactate was reduced $(P<0.08)$ by oil infusion. Arterial concentration of $\mathrm{L}^{-}$ lactate was unaffected by oil infusion but was lower in ELAC than in MLAC $(P<0.01)$. Net removal of L-lactate by the liver was greater $(P<0.01)$ in ELAC than in MLAC (Table 4) and, as there was no effect of stage of lactation on net PDV release of L-lactate $(P>0.64)$, net TSP release of L-lactate was lower in ELAC than in MLAC $(P<0.01$ [Table 4]). There were no effects of either stage of lactation or oil infusion on arterial concentration $(P>0.13)$ or net PDV, liver, or TSP flux of BHBA $(P>$ 0.40 [Table 4]).

Arterial NEFA concentrations were increased by oil infusion $(P<0.02)$ and were greater in ELAC than in MLAC $(P<0.01$ [Table 4]). Greater arterial concentrations of NEFA during oil infusion were associated with increased net uptake of NEFA by liver $(P<0.02)$. Overall there was a net TSP uptake of NEFA that was increased by oil infusion $(P<0.02)$. Net PDV release and liver removal of NEFA were greater in ELAC than in MLAC $(P<0.02)$, such that net TSP removal of NEFA was not affected by lactation stage $(P>0.99)$.

\section{DISCUSSION}

\section{Packed-cell Volume, Blood Flow, and Blood Gas Exchange}

Possible explanations for the decrease in PCV and hemoglobin during abomasal oil infusion include the 
Table 4. Arterial concentrations $(\mu \mathrm{M})$ and net flux of plasma metabolites across portal-drained viscera (PDV), liver, and total splanchnic (TSP) tissues during abomasal infusion of water or oil at an average of 55 (early lactation [ELAC]) and 111 (midlactation [MLAC]) d postpartum.

\begin{tabular}{|c|c|c|c|c|c|c|c|c|}
\hline & \multicolumn{4}{|c|}{ Lactation stage } & \multirow[b]{3}{*}{ SEM } & \multicolumn{3}{|c|}{ Significance, $P<$} \\
\hline & \multicolumn{2}{|c|}{ ELAC } & \multicolumn{2}{|c|}{ MLAC } & & \multirow{2}{*}{$\begin{array}{l}\text { Lactation } \\
\text { stage }\end{array}$} & \multirow[b]{2}{*}{ Infusion } & \multirow{2}{*}{$\begin{array}{l}\text { Stage } \times \\
\text { infusion }\end{array}$} \\
\hline & Water & Oil & Water & Oil & & & & \\
\hline \multicolumn{9}{|c|}{ Arterial concentration, $\mu M$} \\
\hline Glucose & 3520 & 3440 & 3670 & 3540 & 31 & 0.01 & 0.01 & 0.37 \\
\hline L-Lactate & 344 & 312 & 448 & 417 & 30 & 0.01 & 0.32 & 0.99 \\
\hline BHBA & 800 & 807 & 745 & 749 & 33 & 0.13 & 0.87 & 0.97 \\
\hline NEFA & 121 & 159 & 73 & 113 & 13 & 0.01 & 0.02 & 0.95 \\
\hline \multicolumn{9}{|c|}{ Net PDV flux, $\mathrm{mmol} / \mathrm{h}$} \\
\hline Glucose & -2.9 & -10.6 & -19.2 & -22.8 & 8.95 & 0.15 & 0.56 & 0.83 \\
\hline L-Lactate & 205 & 209 & 219 & 206 & 11.3 & 0.64 & 0.68 & 0.50 \\
\hline BHBA & 264 & 269 & 261 & 264 & 11.9 & 0.74 & 0.77 & 0.95 \\
\hline NEFA & 23 & 26 & 10 & 17 & 3.2 & 0.01 & 0.17 & 0.62 \\
\hline \multicolumn{9}{|c|}{ Net liver flux, $\mathrm{mmol} / \mathrm{h}$} \\
\hline Glucose & 932 & 873 & 832 & 768 & 28 & 0.01 & 0.06 & 0.90 \\
\hline L-Lactate & -181 & -230 & -42 & -89 & 21 & 0.01 & 0.05 & 0.97 \\
\hline BHBA & 382 & 368 & 362 & 331 & 32 & 0.40 & 0.51 & 0.80 \\
\hline NEFA & -48 & -61 & -36 & -48 & 4.3 & 0.02 & 0.02 & 0.92 \\
\hline \multicolumn{9}{|c|}{ Net TSP flux, mmol/h } \\
\hline Glucose & 929 & 865 & 811 & 745 & 30 & 0.01 & 0.06 & 0.97 \\
\hline L-Lactate & 25 & 19 & 178 & 117 & 27 & 0.01 & 0.08 & 0.77 \\
\hline BHBA & 644 & 636 & 621 & 591 & 39 & 0.42 & 0.65 & 0.79 \\
\hline NEFA & -25 & -33 & -26 & -32 & 2.4 & 0.99 & 0.02 & 0.63 \\
\hline
\end{tabular}

blood sampling schedule and volume of blood removed, as sampling during oil infusion always followed a control sampling. Portal and liver plasma and blood flows were increased by oil infusion and were greater in ELAC than in MLAC. Overall, the hepatic artery accounted for $20 \%$ of liver blood flow, which is similar to the proportion reported for cows in early and midlactation (Reynolds, 1995), but higher than the contribution observed in cows in late lactation (Reynolds et al., 1994) or growing cattle (Reynolds, 1995). A greater proportional contribution of the hepatic artery to liver blood flow has been suggested to be a reflection of the increased metabolic activity and $\mathrm{O}_{2}$ requirements of the liver during early lactation (Reynolds, 1995). The high rates of liver blood and plasma flow observed in the present study are comparable to measurements obtained in early lactation cows (Bach et al., 2000) at DMI similar to the present study. Bach et al. (2000) also observed a ratio of portal vein to total liver plasma flow of 0.8 .

The effect of oil infusion on liver plasma flow in the present study was attributed to metabolizable energy (ME) intake during the blood sampling period or to neural or hormonal responses to postruminal oil infusion (Benson and Reynolds, 2001). While oil infusion decreased daily DMI in our study, the reduction occurred late in the day and before the morning milking, and thus feed DMI during the period of sampling was not affected (Benson et al., 2001). In addition, decreases in blood PCV and hemoglobin and arterial $\mathrm{O}_{2}$ concentration also may have contributed to the increase in blood flow during oil infusion. Assuming a constant $\mathrm{O}_{2}$ extraction efficiency, splanchnic blood flow may have increased during oil infusion to compensate for decreased blood $\mathrm{O}_{2}$ level and restore $\mathrm{O}_{2}$ supply. However, this theory is not supported by work elsewhere. Experimentally induced anemia in pregnant sheep had no effect on blood flow to tissues comprising the TSP (Edelstone et al., 1987), or PDV blood flow and $\mathrm{O}_{2}$ removal in preruminant lambs, where PDV $\mathrm{O}_{2}$ extraction efficiency varied inversely with PCV and $\mathrm{O}_{2}$ supply (Holzman et al., 1985). In humans, increased splanchnic blood flow following ingestion of oil was accompanied by an increase in blood PCV, suggesting other factors are responsible for the increased flow observed (Brundin, 1998). In this regard, increased absorption of oleic acid increases blood flow to the mucosa and muscularis of the jejunum of dogs via signals independent of changes in intestinal metabolism (Chou et al., 1985). These authors theorized that oleate effects on intestinal blood flow might facilitate increased lymph flow, aiding any oleate absorption into mesenteric veins. In the present study, increased liver blood flow during oil infusion was due totally to increased portal vein flow and not accompanied by changes in PDV $\mathrm{O}_{2}$ removal, implying a specific effect on PDV blood flow.

The RQ for the PDV (0.39) was low compared to other studies in lactating cows. A mean value of 0.56 ( 0.71 to 0.43 ) was reported for the PDV of lactating cows (Reynolds et al., 1988a), and a value of 2.3 was calculated from 
the data of Baird et al. (1975). The variability of these values may be due in part to the variability of sampling and measurement technique, as well as variations in gut lumen and blood $\mathrm{CO}_{2}$ exchange. The net release of $\mathrm{CO}_{2}$ by the PDV tissues can be attributable to a number of sources, including gut fermentation, respiratory metabolism in gut tissues, and bicarbonate in saliva. In addition, it is required for absorption of VFA and can be transferred directly from arterial blood to the lumen of the gut (Reynolds et al., 1988a). For these reasons, "conclusions concerning the metabolism by tissue cannot be made" from net PDV flux of $\mathrm{CO}_{2}$ (Pell et al., 1986).

The liver, like the PDV, is highly metabolically active and in the present study consumed amounts of $\mathrm{O}_{2}$ similar to the PDV. The RQ for the liver was also low (0.64) compared with previous studies ( 0.72 for Reynolds et al., 1988a; 0.90 for Baird et al., 1975) in lactating cows. Liver release of $\mathrm{CO}_{2}$ underestimates total production to the extent that $\mathrm{CO}_{2}$ is used for metabolic processes, such as urea synthesis from ammonia (Stryer, 1981). Neither $\mathrm{O}_{2}$ consumption nor net $\mathrm{CO}_{2}$ release by the liver or TSP tissues was affected by oil infusion. Brundin (1998) also noted no difference in TSP $\mathrm{O}_{2}$ consumption after oral or intravenous administration of vegetable oil in humans, despite an increase in blood flow.

Removal of $\mathrm{O}_{2}$ by the PDV was not affected by stage of lactation, but the liver removed more $\mathrm{O}_{2}$ in ELAC. This in part reflects increased liver glucose synthesis, NEFA removal, and perhaps oxidation. This increase in liver $\mathrm{O}_{2}$ use may also explain the increase in liver blood flow observed in early lactation. Although blood flow to the PDV and liver is highly correlated with DMI, liver blood flow was elevated in ELAC despite similar DMI compared with MLAC. This implies that the increase in liver blood flow in ELAC was a result of the metabolic activity and $\mathrm{O}_{2}$ requirement when milk yield and metabolic demands on the liver were increased.

\section{Effects of LCFA Infusion}

PDV nutrient metabolism. Although daily DMI was reduced by oil infusion, net PDV absorption of total VFA was unaffected. As discussed previously, DMI during the 8-h sampling period was unaffected (Benson et al., 2001), and therefore, the supply of fermentable substrates to the rumen, and subsequently total VFA absorption, would be expected to be similar. However, net PDV absorption of branched-chain VFA and ammonia were increased by oil infusion. These results are difficult to explain, as net PDV release of the other VFA was largely unaffected. Possible explanations for increased net PDV absorption of branched-chain VFA and ammonia attributable to oil infusion include an inhibition of gut motility caused by increased intestinal oil supply (Nicholson and
Omer, 1983), which may have altered the extent and pattern of fermentation, as well as oxidative metabolism of the gut tissues. Alternatively, hormonal and metabolic effects of oil infusion may have altered the metabolism of PDV tissues, and thereby branched-chain VFA and ammonia release. In addition, inhibitory effects of any unabsorbed oil on hindgut fermentation and microbial growth, and thus ammonia utilization, may have increased net ammonia absorption.

In spite of greater portal vein blood flow during oil infusion, net PDV removal of $\mathrm{O}_{2}$ was unchanged. In addition, oil infusion had no effect on the net PDV release of $\mathrm{CO}_{2}, \mathrm{BHBA}$, and L-lactate, which are all products of PDV metabolism of VFA and glucose. These observations suggest that during sampling the metabolic activity of the PDV was dictated more by feed DMI and fermentable energy supply than by total ME and oil infusion, and that increases in blood flow during oil infusion were not a consequence of changes in the metabolic activity of the gut.

Net PDV glucose flux was also not affected by oil infusion and was negative, indicating greater use of arterial glucose than glucose absorption into the portal vein. However, during the course of blood sampling, net PDV glucose flux increased such that there was a shift from net use of glucose to net release approximately $2 \mathrm{~h}$ after feeding (Figure 1). This may reflect a postprandial increase in rumen outflow of undigested starch to the small intestine. There was no evidence of a postprandial response of net L-lactate release by the PDV (data not shown), but there was a marked increase in net PDV release of propionate after feeding (Figure 2), suggesting postprandial responses of propionate, but not L-lactate, were dictated by rumen fermentation. This implies that much of the L-lactate absorbed into the portal vein was a product of glycolysis and not silage intake, fermentation, or propionate metabolism during absorption.

Net PDV NEFA flux was increased by oil infusion, which may be due to increased release of NEFA from PDV-associated fat. Only a small proportion of dietary NEFA are absorbed directly into the portal vein, as the majority of NEFA with carbon chain length greater than 12 are absorbed into lymph. Gagliostro and Chilliard (1991) observed increased lipolytic activity of adipose tissue sampled from lactating cows given a duodenal infusion of rapeseed oil, which may explain the increase in net PDV release of NEFA during oil infusion in our study.

Liver metabolism. Grummer and Carroll (1991) proposed that fat supplementation spares glucose from oxidation and that this glucose may be utilized for lactose synthesis and milk production. In the present study, milk production was unaffected by oil infusion despite a decrease in daily DMI (Benson et al., 2001) and liver 

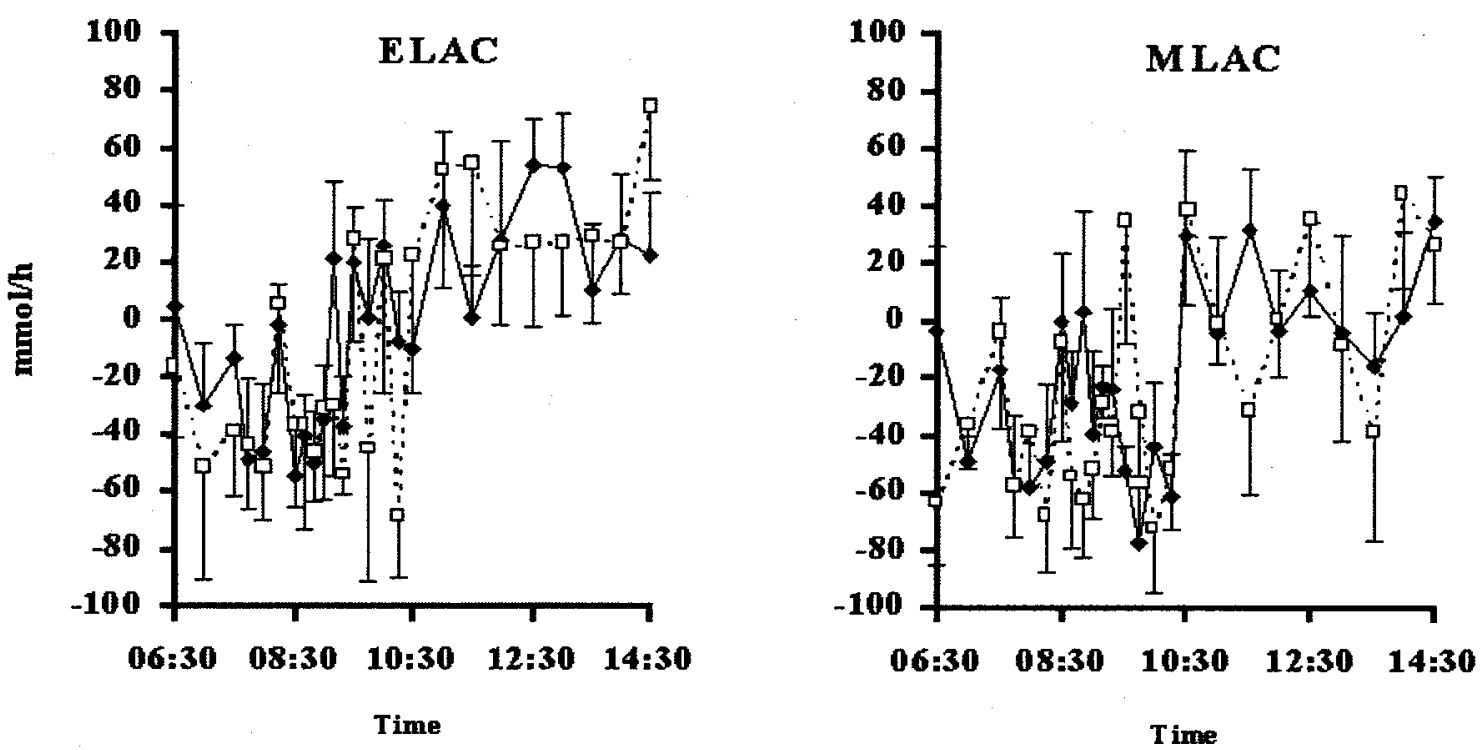

Figure 1. Patterns of net portal-drained viscera glucose flux ( $\mathrm{mmol} / \mathrm{h})$ during an 8-h sampling period at the end of 7-d abomasal infusions of water (solid line) or oil (dashed line) in lactating dairy cows at a mean of 55 (early lactation [ELAC]) and 111 (midlactation [MLAC]) d postpartum. Cows were fed after sampling at $0830 \mathrm{~h}$.

glucose production; therefore, a larger proportion of liver glucose release was used for milk synthesis. Oil infusion decreased liver glucose output without affecting DMI and liver VFA removal during the 8-h sampling period (Table 2). This suggests that abomasal oil infusion had inhibitory effects on liver glucose production independent of precursor supply during sampling.

Abomasal oil infusion increased the maximum possible contribution of propionate and L-lactate to liver glucose output. This reflects the decrease in liver glucose output and the increase in L-lactate uptake by the liver and suggests a decrease in the contribution of other precursors not measured in the current study (amino acids, glycerol, or pyruvate [Lomax and Baird, 1983]). Alternatively, oil infusion may have caused an increase in the nonglucogenic use of propionate, lactate, or other potential sources of glucose carbon. Increases in insulin and decreases in glucagon could also cause a reduction in liver glucose production (Brockman and Laarveld, 1986), but, in the present study, arterial concentration of insulin was reduced by oil infusion, whereas net liver removal of pancreatic glucagon was increased (Benson and Reynolds, 2001). These changes in pancreatic hormones do not explain the decrease in liver glucose release, but they do provide an explanation for the increase in liver Llactate removal when oil was infused. L-Lactate is utilized via lactate dehydrogenase and pyruvate carboxylase, and the later enzyme is stimulated by pancreatic glucagon (Brockman and Laarveld, 1986).
In vitro work using hepatocytes from sheep, goats, and calves has shown that under certain conditions specific LCFA (oleate and palmitate) can stimulate gluconeogenesis from propionate (Faulkner and Pollock, 1986; Aiello and Armentano, 1988), without altering the glucogenic use of L-lactate (Aiello and Armentano, 1988). However, in the present study, oil infusion decreased liver glucose release and plasma glucose concentration, perhaps via decreased daily DMI or a decreased glucose requirement, rather than a direct effect of infused LCFA on liver metabolism. Drackley et al. (1992) noted a tendency for plasma glucose concentration to linearly decrease with increasing unsaturation and chain length of abomasally infused LCFA, which they attributed to decreased DMI.

There was a net removal of total VFA and release of acetate by the liver, which was unaffected by oil infusion. Net liver removal of branched-chain VFA was increased by oil infusion, but this accompanied an equivalent increase in their net PDV release, and thus net TSP output was unchanged. As often noted (Reynolds, 1995; Nozière et al., 2000), it appeared that the liver removed VFA (with the exception of acetate) in proportion to their supply from the gut. This is illustrated by the patterns of net PDV absorption and liver removal of propionate across the 8-h sampling period (Figure 2). Postprandial increases in net PDV release of propionate were mirrored by increased net liver removal, and, therefore, little variation in net TSP release was observed. 

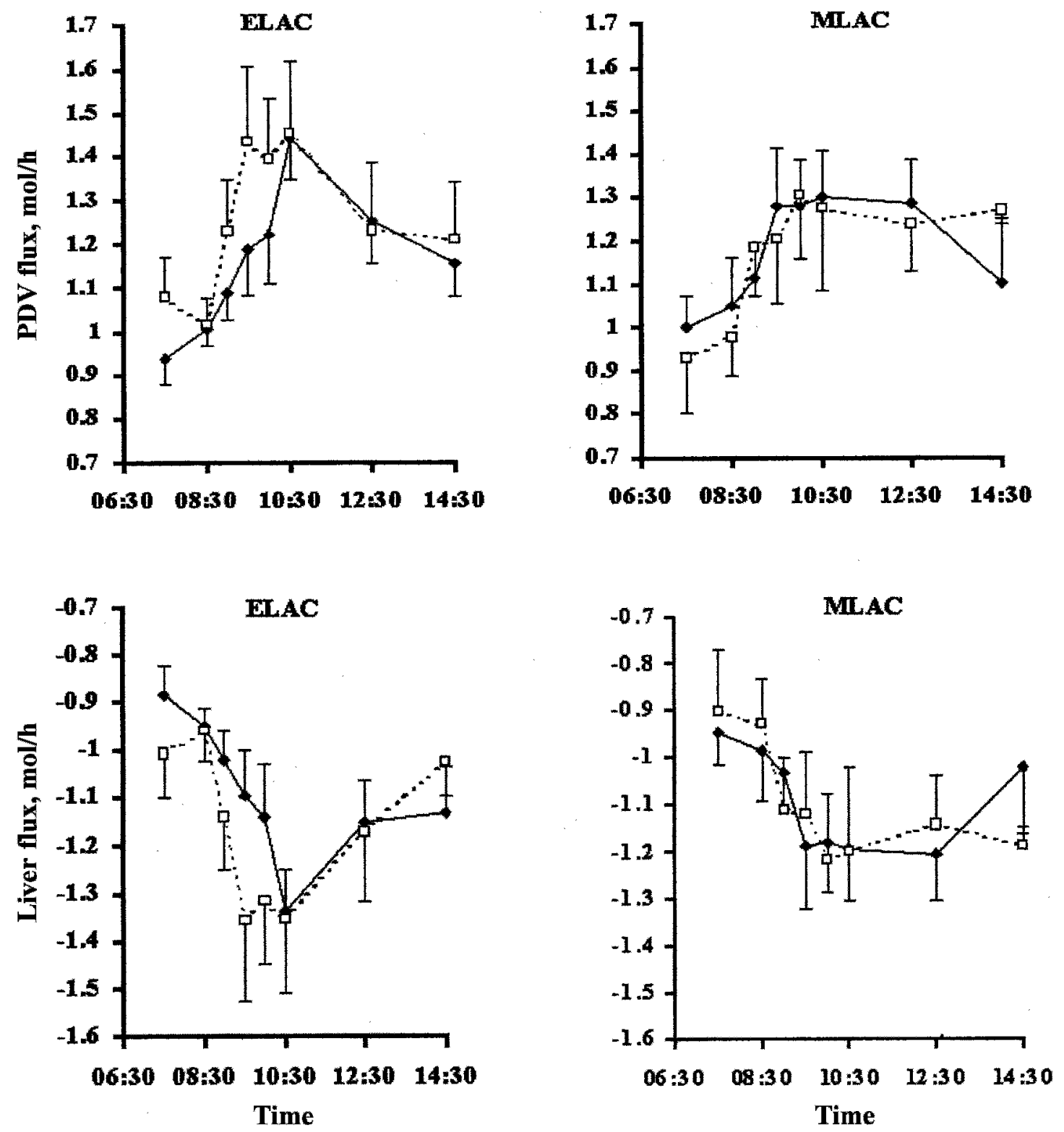

Figure 2. Patterns of net portal-drained viscera (PDV) (a) and liver (b) propionate fluxes (mol/h) during an 8-h sampling period at the end of 7-d abomasal infusions of water (solid line) or oil (dashed line) in lactating dairy cows at a mean of 55 (early lactation [ELAC]) and 111 (midlactation [MLAC]) d postpartum. Cows were fed after sampling at $0830 \mathrm{~h}$.

Net removal of NEFA by the liver was increased by oil infusion, presumably due to increased arterial concentration and supply from the PDV, as NEFA are removed by the liver in proportion to their supply by blood (Emery et al., 1992). BHBA is a product of NEFA and n-butyrate metabolism by the liver, but oil infusion had no effect on BHBA production by the liver. The maximum possible contribution of n-butyrate and NEFA removed by the liver to BHBA released was greater than $100 \%$ during oil infusion, perhaps reflecting an increase in-liver utilization of NEFA via oxidation or triglyceride synthesis
(Emery et al., 1992). In the present study, an increase in the oxidation of NEFA and other metabolites may have contributed to the depression in daily DMI observed when oil was infused. In nonruminants, increases in liver ATP levels due to LCFA oxidation depress appetite and intake (Scharrer and Langhans, 1986; Friedman, 1998).

\section{Effects of Stage of Lactation}

PDV nutrient metabolism. Lomax and Baird (1983) and Reynolds et al. (1988a) have shown increases in 
portal vein blood flow and net PDV absorption of VFA and L-lactate in lactating cows compared to nonlactating cows. This is largely the result of increased DMI, as numerous studies have shown linear relationships between DM or ME intake and net PDV release of VFA and other nutrients (Lomax and Baird, 1983; Nozière et al., 2000). However, there has been little research measuring changes in splanchnic metabolism of dairy cows at differing stages of lactation. In the present experiment, DMI and net PDV absorption of total VFA, acetate, propionate, L-lactate, and BHBA were similar in ELAC ( 8 wk) and MLAC (16 wk). Net PDV absorption of ammonia is highly correlated with $\mathrm{N}$ intake (Reynolds, 1995) and was similarly unaffected by stage of lactation in the present study. In contrast, absorption of n-butyrate, branched-chain VFA, and n-valerate were greater in ELAC. Reasons for this specific increase in the PDV absorption of longer-chain VFA are uncertain. The response may be related to longer-term adaptation of the rumen microflora to higher DMI as lactation progressed, effects of water intake associated with higher milk yield in ELAC on rumen fermentation, or changes in gut tissue mass and subsequent metabolism of absorbed VFA.

Net PDV release of NEFA was greater in ELAC compared to MLAC. Reynolds et al. (1988a) reported a decrease in net PDV release of NEFA between wk 4 and 8 of lactation. These differences in net PDV release of NEFA were probably due to an increase in lipolysis of adipose tissue drained by the portal vein associated with greater milk energy yield (Benson et al., 2001) or lower DMI (Reynolds et al., 1988a) in ELAC, and thus reduced tissue energy balance.

Liver metabolism. Net liver removal of propionate was not affected by stage of lactation, but net liver removal of n-butyrate, branched-chain VFA and n-valerate were greater in ELAC, a consequence of the increase in their net PDV release. Net acetate release by the liver was also greater in ELAC compared with MLAC. This may be attributable to increased NEFA removal and metabolism. However, abomasal oil infusion also increased net liver removal of NEFA but had no effect on net liver release of acetate. In very ELAC, greater liver removal of NEFA would be expected to be associated with more NEFA oxidation and ketone body synthesis, but there was no effect of stage of lactation on net liver release of BHBA in the present study. Net glucose release by the liver was higher in ELAC when milk yield and glucose requirement for milk synthesis were greater (Benson et al., 2001), but arterial glucose concentration was lower, perhaps due to an increased use for milk synthesis. In ELAC, greater glucose release by the liver was associated with more liver removal of L-lactate, and thus a decreased net TSP release. This suggests that the metabolic changes associated with increased milk production in ELAC result in a requirement for additional L-lactate to restore liver carbon balance (Reynolds, 1995). Greater L-lactate removal by the liver in ELAC was associated with increased net liver removal of pancreatic glucagons (Benson and Reynolds, 2001), but in contrast to the response to abomasal oil infusion, increased glucagon removal by the liver in ELAC was associated with greater net glucose release.

Increased liver removal of L-lactate in ELAC may in part reflect an increase in Cori cycling of glucose and lactate between the liver and glycolysis in other tissues, as occurs during starvation (Stryer, 1981). In MLAC, when the cows were in more positive tissue-energy balance (calculated tissue-energy balance increased by 13.2 $\mathrm{MJ} / \mathrm{d}$ ), an increased liver-carbon balance and TSP release of lactate to peripheral tissues may support more body fat synthesis in lactating dairy cows, as occurs with increased intake level in growing ruminants (Prior, 1978). Similarly, differences in liver lactate removal, and thus net TSP lactate release, have been positively associated with increased tissue energy and fat retention in growing cattle (Reynolds et al., 1991; Reynolds, 1995). In the present study, net TSP flux of NEFA was negative, representing liver removal of NEFA from peripheral tissues, and not affected by stage of lactation. However, tissue exchanges of blood NEFA do not account for LCFA exchange via lipoproteins.

\section{CONCLUSIONS}

To our knowledge, this study was the first to measure the effect of postruminal LCFA supply on net flux of nutrients across the PDV and liver in lactating dairy cows. Abomasal infusion of a mixture of sunflower and rapeseed oils had a number of effects on splanchnic metabolism, including increases in PDV and liver blood flow, which were not associated with measurable changes in $\mathrm{O}_{2}$ removal. Increased abomasal oil supply increased liver removal of L-lactate and NEFA, but liver glucose release was decreased. Comparison of net PDV and liver flux of nutrients between the two stages of lactation were generally consistent with a lack of change in DMI, and thus net PDV metabolism, coupled with an increased metabolic activity of the liver to support greater milk yield in ELAC. In contrast to the effects of oil infusion, greater liver blood flow in ELAC was associated with an increased liver removal of $\mathrm{O}_{2}$, whereas increases in net liver removal of lactate and NEFA in ELAC accompanied an increase in liver glucose release. With the exception of net PDV release of acetate, the metabolic response to postruminal supply of LCFA did not differ between 8 and 16 wk postpartum. 


\section{ACKNOWLEDGMENTS}

The dedicated support of D. Humphries and technical staff of the CEDAR Metabolism Unit in the daily management and care of cows and conduct of this study is gratefully acknowledged. J. A. Benson was funded by a UK Ministry of Agriculture, Fisheries and Food Postgraduate Studentship.

\section{REFERENCES}

Aiello, R. J., and L. E. Armentano. 1988. Fatty acid effects on gluconeogenesis in goat, calf, and guinea pig hepatocytes. Comp. Biochem. Physiol. 91B:339-344.

Bach, A., G. B. Huntington, S. Calsamiglia, and M. D. Stern. 2000. Nitrogen metabolism of early lactation cows fed diets with two different levels of protein and different amino acid profiles. J. Dairy Sci. 83:2585-2595.

Baird, G. D., H. W. Symonds, and R. Ash. 1975. Some observations on metabolite production and utilisation in vivo by the gut and liver of adult dairy cows. J. Agric. Sci. (Camb.) 85:281-296.

Benson, J. A., and C. K. Reynolds. 2001. Effects of abomasal fat infusion on splanchnic metabolism of pancreatic and gut hormones in dairy cows. J. Dairy Sci. 84:1488-1500.

Benson, J. A., C. K. Reynolds, D. J. Humphries, S. M. Rutter, and D. E. Beever. 2001. Effects of abomasal infusion of long chain fatty acids on intake, feeding behaviour and milk production in dairy cows. J. Dairy Sci. 84:1182-1191.

Brockman, R. P., and B. Laarveld. 1986. Hormonal regulation of metabolism in ruminants: A review. Livestock Prod. Sci. 14:313-334.

Brundin, T. 1998. Whole body and splanchnic metabolic, circulatory, and thermal effects of oral vs. intravenous fat administration. Am. J. Physiol. 274:E684-E691.

Chou, C. C., R. A. Nyhor, P. R. Kvietys, S. P. Sit, and R. H. Gallavan. 1985. Regulation of regional blood flow and oxygenation during glucose and oleic acid absorption. Am. J. Physiol. 249:G691-G701.

Drackley, J. K., T. H. Klusmeyer, A. M. Trusk, and J. H. Clark. 1992. Infusion of long-chain fatty acids varying in saturation and chain length into the abomasum of lactating dairy cows. J. Dairy Sci. 75:1517-1526.

Edelstone, D. I., M. E. Pauline, J. J. Maijovec, and M. Hagberg. 1987. Effects of maternal anemia on cardiac output, systemic oxygen consumption, and regional blood flow in pregnant sheep. Am. J. Obstet. Gynecol. 156:740-748.

Emery, R. S., J. S. Liesman, and T. H. Herdt. 1992. Metabolism of long chain fatty acids by ruminant liver. J. Nutr. 122:832-837.

Faulkner, A., and H. T. Pollock. 1986. Propionate metabolism and its regulation by fatty acids in ovine hepatocytes. Comp. Biochem. Physiol. 84B:559-563.

Friedman, M. I. 1998. Fuel partitioning and food intake. Am. J. Clin. Nutr. 67(Suppl.):513S-518S.

Gagliostro, G., and Y. Chilliard. 1991. Duodenal rapeseed oil infusion in early and mid lactation dairy cows. 4 . In vivo and in vitro adipose tissue lipolytic responses. J. Dairy Sci. 74:1893-1899.

Grummer, R. R., and D. J. Carroll. 1991. Effects of dietary fat on metabolic disorders and reproductive performance of dairy cattle. J. Anim. Sci. 69:3838-3852.

Gutman, I., and A. W. Wahlfeld. 1974. L-lactate determination with lactate dehydrogenase and NAD. Pages 1464-1468 in Methods of
Enzymatic Analysis, Vol. 3. H. U. Bergmeyer, ed. Academic Press, London, UK.

Holzman, I. R., B. Tabata, and D. I. Edelstone. 1985. Effects of varying hematocrit on intestinal oxygen uptake in neonatal lambs. Am. J. Physiol. 248:G432-G436.

Kun, E., and E. B. Kearney. 1974. Ammonia. Pages 1802-1806 in Methods of Enzymatic Analysis, Vol. 4. H. U. Bergmeyer, ed. Academic Press, London, UK.

Leplaix-Charlat, L., D. Durand, and D. Bauchart. 1996. Effects of diets containing tallow and soybean oil with and without cholesterol on hepatic metabolism of lipids and lipoproteins in the preruminant calf. J. Dairy Sci. 79:1826-1835.

Lomax, M. A., and G. D. Baird. 1983. Blood flow and nutrient exchange across the liver and gut of the dairy cow. Br. J. Nutr. 49:481-496.

Nicholson, T., and S. A. Omer. 1983. The inhibitory effect of intestinal infusions of unsaturated long-chain fatty acids on forestomach motility of sheep. Br. J. Nutr. 50:141-149.

Nozière, P., D. Rémond, L. Bernard, and M. Doreau. 2000. Effect of underfeeding on metabolism of portal-drained viscera in ewes. Brit. J. Nutr. 84:821-828.

Oddy, V. H., J. M. Gooden, and E. F. Annison. 1984. Partitioning of nutrients in Merino ewes. I. Contribution of skeletal muscle, the pregnant uterus and the lactating mammary gland to total energy expenditure. Austr. J. Biol. Sci. 237:375-388.

Palmquist, D. L. 1994. The role of dietary fats in efficiency of ruminants. J. Nutr. 124:1377S-1382S.

Pell, J. M., E. M. Caldarone, and E. N. Bergman. 1986. Leucine and $\alpha$ ketoisocaproate metabolism and interconversions in fed and fasted sheep. Metabolism 35:1005-1016.

Prior, R. L. 1978. Effect of level of feed intake on lactate and acetate metabolism and lipogenesis in vivo in sheep. J. Nutr. 108:926-935.

Reynolds, C. K. 1995. Quantitative aspects of liver metabolism in ruminants. Pages 351-371 in Ruminant Physiology: Digestion, Metabolism, Growth and Reproduction: Proc. 8th Int. Symp. Ruminant Physiol. W. V. Engelhardt, S. Leonhard-Marek, G. Breves, and D. Giesecke, ed. Ferdinand Enke Verlag, Stuttgardt, Germany.

Reynolds, C. K., G. B. Huntington, and H. F. Tyrrell. 1994. Effects of feeding maize grain harvested at two stages of maturity on net nutrient metabolism by splanchnic tissues of lactating dairy cows. Anim. Prod. 58:433-434. (Abstr.).

Reynolds, C. K., G. B. Huntington, H. F. Tyrrell, and P. J. Reynolds. 1988a. Net metabolism of volatile fatty acids, D- $\beta$-hydroxybutyrate, nonesterified fatty acids, and blood gases by portal-drained viscera and liver of lactating cows. J. Dairy Sci. 71:2395-2405.

Reynolds, C. K., G. B. Huntington, H. F. Tyrrell, and P. J. Reynolds. 1988b. Net portal-drained visceral and hepatic metabolism of glucose, L-lactate, and nitrogenous compounds in lactating Holstein cows. J. Dairy Sci. 71:1803-1812.

Reynolds, C. K., H. F. Tyrrell, and P. J. Reynolds. 1991. Effects of diet forage-to-concentrate ratio and intake on energy metabolism in growing beef heifers: Net nutrient metabolism by visceral tissues. J. Nutr. 121:1004-1015.

Reynolds, P. J., C. K. Reynolds, and G. B. Huntington. 1986. Determination of volatile fatty acids, lactate and $\beta$-hydroxybutyrate in blood by ion exchange and gas chromatography. J. Anim. Sci. 63(Suppl. 1):424. (Abstr.).

SAS User's Guide: Statistics. Version 6.12 Edition. 1999. SAS Inst. Inc., Cary, NC.

Scharrer, E., and W. Langhans. 1986. Control of food intake by fatty acid oxidation. Am. J. Physiol. 250:R1003-R1006.

Stryer, L. 1981. Biochemistry. W. H. Freeman and Company, New York, NY. 